\title{
Amplification of health risk messages in leading Philippine newspapers
}

\author{
Jedess Miladel C. Nuñez and Rotacio S. Gravoso \\ Department of Development Communication, College of Agriculture, \\ Leyte State University, Baybay, Leyte 6521-A, Philippines
}

\begin{abstract}
This study aimed to find out the coverage and amplification of health risk messages of leading Philippine newspapers: Philippine Daily Inquirer, The Philippine Star, and Manila Bulletin. Data were gathered through a content analysis of health risk articles published by those newspapers in 2005 .

Results revealed that the health risk articles published in 2005 by the three newspapers focused on bird flu, dengue fever, food poisoning and meningococcemia. However, the three newspapers did not give prominence to health risk articles. In terms of sources of information, most of the articles quoted experts and government officials but were prompted by public experiences. Most of the articles assigned blame or responsibility to organizations rather than individuals.

The lexical content analysis using the Language Inquiry and Word Count (LIWC) showed that negative emotion words, words linked to people's ratings of anxiety, were present in health risk articles, indicating intensification of the health risk. For bird flu articles, most of the negative words were in the pre-peak and post-peak periods, while for dengue fever, in the peak period. For food poisoning and meningococcemia, most negative emotion words in the articles were published during the post-peak period.
\end{abstract}

Keywords: health risk messages, risk amplification, risk intensification, negative emotion words, Philippine newspapers, content analysis

Correspondence: R. S. Gravoso Present Address: Department of Development Communication, College of Agriculture, Leyte State University, Visca, Baybay, Leyte 6521-A, Philippines. Tel. No.(053) 335-2625; E-mail.gravoso_ph@yahoo.com

DOI: $10.32945 /$ atr2917.2007 


\section{INTRODUCTION}

Like other mass media, the newspaper plays strategic roles in our society. Apart from serving as venue for discussion of public issues and as watchdog of the abuses of powers, a newspaper brings useful knowledge and information to its readers. Among these information are risk messages, or in simple terms, messages about the possibility of encountering harm or loss. In fact, extant literature shows that risk messages are becoming dominant in newspapers (e.g., Waishwell and Lowrie, 2005; Cassels et al., 2003; Nilsson et al., 1997).

Reporting risks by newspapers is, however, determined by several factors. Among these are factors associated with newsworthiness and ratings such as controversy, conflict, disagreements, and wrongdoings. In general, journalists give greater coverage to incidents with the greatest signal value or threat potential.

Many claim that media amplify risks as they sensationalize issues (Breakwell et al., 2001). This claim may be justified because as Covello (2005) argues, journalists typically give greater coverage to events that are dramatic and sensational, especially those that cause major disruptions in the routine functioning of the society. Such a reaction is expected as sensationalized coverage can amplify risks, hamper efforts to respond to a disaster, and reduce social emphasis on mitigation. Thus, media are being blamed on the oftennoted differences between the scientists and the lay public's perception of risk. This is because media can enhance cultural predispositions to exaggerate certain hazards and deny others. They tend to highlight existing concerns, uncertainties and conflicts, rarely question the legitimacy of any source, and present all sources on a rather equal footing (Rodrigue, 2001).

In the Philippines, owing to the heightened consciousness for health issues, the country's leading newspapers - Philippine Daily Inquirer, Manila Bulletin and The Philippine Star-- have been publishing health-related articles. Built into these articles are health risk messages. The leading Philippine newspapers, therefore, could be good subjects for exploring how health risks are covered and if these health risks are amplified. More specifically, the leading Philippine newspapers could help provide answers to the following questions: 1) In 2005, what health risks have been reported by these newspapers? 2) Were negative emotion words used by these newspapers in reporting health risks?

To answer these questions, this study used the social amplification of risk framework (SARF). SARF attempts to integrate the dynamic social elements of the risk perception process (Kasperon et al., 1988). It hypothesizes that 
information processes, institutional structures, social-group behavior, and individual responses shape the social experience of risk. This means that as social stations, the Philippine newspapers may intensify or attenuate risks. In this study, risk amplification, either intensification or attenuation, was measured through the Linguistic Inquiry and Word Count (LIWC), a computer-based program that detects the presence of negative emotion words. An increase in the number of negative words was taken to mean that the risk was amplified.

\section{METHODS}

\section{Determining the health risk coverage of the newspapers}

A content analysis was conducted to find out the coverage of health risk articles in the three national newspapers. The content analysis involved news attention, news making, access to voice, assignment of responsibility and blame, frequency, space allocation of health articles. Table 1 served as guide for the analysis.

Sample issues from each of the three newspapers were drawn through random sampling. Paper slips numbered 1-31, representing the days in a month, were rolled and placed in a box. From these, six slips (representing $20 \%$ of the total number of issues each month) were drawn. This was done 12 times to get representative samples for each month. Using this procedure, the sample issues totaled to 216. Articles dealing with health risk issues were then subjected to content analysis.

The one-way ANOVA was used to determine the differences of the three newspapers in terms of space allotted to health risks, number of health risk articles published, and space allotted to the health articles across the three time periods (pre-peak, peak, and post-peak).

\section{Determining the negative emotion words in health risk messages}

All health risk articles identified in the content analysis were subjected to lexical analysis. Articles were encoded using Microsoft Word and then processed by LIWC. A computer-based program, LIWC was developed with more psychology-based research intentions. It places greater emphasis on emotional and psychological language in a text. The LIWC showed the percent of words according to seven categories. Only the data of negative 
Table 1. Guide in determining the health risk messages in the newspapers

\begin{tabular}{ll}
\hline Variable & \multicolumn{1}{c}{ Method of Measurement } \\
\hline News attention & $\begin{array}{l}\text { Health articles were classified according to the areas of risks } \\
\text { covered by these articles. }\end{array}$ \\
News making & $\begin{array}{l}\text { Health risk articles were classified based on what prompts } \\
\text { the risk story, whether activities of scientific and academic } \\
\text { communities or experiences of the public. }\end{array}$
\end{tabular}

Access to voice

Health risk articles were classified according to the persons quoted in the risk story whether they were expert sources, government officials or ordinary members of the public.

Frequency

Frequency counts were used to determine the total number of health risk articles in each newspaper.

Space allocation

Space allocation for health risk articles were measured using a ruler. The space or area $\left(\mathrm{cm}^{2}\right)$ allotted for each health risk article was obtained by multiplying the length of the article (in $\mathrm{cm}$ ) by the width of the column (in $\mathrm{cm}$ ). The operational formula is:

$$
\begin{array}{r}
\mathrm{SAA}=\text { length of the article }(\mathrm{in} \mathrm{cm}) \mathrm{x} \text { width of the } \\
\text { column (in } \mathrm{cm})
\end{array}
$$

The total space allocation for health risk articles (TSAA) was determined by adding the different space allocation for health risk articles. This was compared with the total space allocation of the paper, which was computed using the formula:

TSA = column width (in $\mathrm{cm}$ ) $\mathrm{x}$ length of the column (in $\mathrm{cm}$ ) $\mathrm{x}$ number of standard columns $\mathrm{x}$ total number of pages.

The percentage of space allotted for health risk articles (PSA) was compared with the total space allocation of the paper. The total space allocation of the newspapers will be computed using the formula:

$$
\mathrm{PSA}=\mathrm{TSAA} \times 100 \mathrm{TSA}
$$

Treatment

In terms of format, health risk articles were classified into straight news, feature, news feature, and commentary. The importance of health risk articles were determined through their placement in the pages of the newspaper. Articles located in the front pages are considered important while those in the inside pages are less important. 
emotion words, which were linked to people's ratings of anxiety, were included in the analysis. In this study, an increase in the number of negative emotion words was taken to mean the article was intensified, thus amplified.

\section{RESULTS AND DISCUSSION}

\section{Health risk articles in the three national newspapers}

In the year 2005, sample issues of the Philippine Daily Inquirer, the Manila Bulletin, and The Philippine Star published a total of 208 health articles. The topics focused on bird flu, dengue fever, food poisoning (particularly cassava poisoning) and meningococcemia. Of these articles, more than half $(64.64 \%)$ were on bird flu. The rest were on dengue fever $(2.67 \%)$, food poisoning (19.23\%), and meningococcemia (13.46\%). Based on the oneway ANOVA, the three newspapers were not significantly different in terms of the number of articles devoted to the four health risks $\left(\mathrm{F}_{(2,205)}=.024, p>.05\right)$.

Table 2 shows that the three newspapers gave top priority to bird flu over other health risk issues. In fact, more than half $(54.69 \%)$ of the health risk articles published by the Inquirer were on bird flu. Only a small number of its articles were on food poisoning (18.75\%) meningococcemia $(15.62 \%)$, and dengue fever (10.94\%). The same trend was observed in the PhilStar.

Table 3 shows that almost half $(49.52 \%)$ of the articles on health risks published in the three newspapers were presented as straight news. News features ranked second (39.90\%), while features (4.81\%) and commentaries (4.81\%) followed. Data showed that the Bulletin published the most number of straight news articles (62 or 29.81\%) compared to the Inquirer (27 or $12.98 \%$ ) and the PhilStar (16 or $7.69 \%$ ). Data also showed that while almost half of the health risk articles were presented in straight news, the three newspapers also provided in-depth analysis and opinion through news features, features and commentaries which, collectively, account for more than half of the health risk articles.

In terms of the total space allotted (TSA), only 0.16 percent of the composite space was occupied by the health risk articles. The Inquirer and the PhilStar gave an almost equal space to the health risks - allocating approximately 0.18 percent. The Bulletin allocated 0.15 percent of its space to health risk articles. 
Table 2. Number of health risk articles published in the leading Philippine newspapers in $2005^{\mathrm{a}}$

\begin{tabular}{lllllll}
\hline Health risk & \multicolumn{5}{c}{ Newspapers } \\
\cline { 2 - 7 } & \multicolumn{7}{l}{ Inquirer $\%$} & Bulletin $\%$ & PhilStar $\%$ \\
\hline Bird flu & 35 & 54.69 & 45 & 47.37 & 26 & 53.06 \\
Dengue & 7 & 10.94 & 21 & 22.10 & 6 & 12.24 \\
Food poisoning & 12 & 18.75 & 19 & 20.00 & 9 & 18.37 \\
Meningococcemia & 10 & 15.62 & 10 & 10.53 & 8 & 16.33 \\
Total & 64 & 100.00 & 95 & 100.00 & 49 & 100.00 \\
\hline${ }^{a}$ No significant differences were detected by the one-way ANOVA $\left(F_{(2,205)}=.024, p>.05\right)$.
\end{tabular}

Table 3. Format used in presenting health risk articles

\begin{tabular}{|c|c|c|c|c|c|c|c|c|}
\hline \multirow[t]{2}{*}{ Format } & \multicolumn{8}{|c|}{ Newspapers } \\
\hline & \multicolumn{2}{|c|}{ Inquirer Rank } & \multicolumn{2}{|c|}{ Bulletin Rank } & \multicolumn{2}{|c|}{ PhilStar Rank } & \multirow{2}{*}{$\begin{array}{l}\text { Total } \\
105\end{array}$} & \multirow{2}{*}{$\frac{\%}{50.48}$} \\
\hline Straight news & 27 & 2 & 62 & 1 & 16 & 2 & & \\
\hline News feature & 29 & 1 & 29 & 2 & 25 & 1 & 83 & 39.90 \\
\hline Feature & 3 & 4 & 3 & 3 & 4 & 3.5 & 10 & 4.81 \\
\hline Commentary & 5 & 3 & 1 & 4 & 4 & 3.5 & 10 & 4.81 \\
\hline Total & & & & & & & 208 & 100 \\
\hline
\end{tabular}

Table 4 shows that the Bulletin gave a total $19,827.40 \mathrm{~cm}^{2}$, while the Inquirer and the PhilStar gave 14,500.74 $\mathrm{cm}^{2}$ and $13,031.65 \mathrm{~cm}^{2}$, respectively. However, the ANOVA showed no significant difference among the three newspapers in terms of space allocated to risk articles $\left(\mathrm{F}_{(2,205)}=2.29, p>.05\right)$.

In terms of space allocated to the different health risks, the three newspapers gave prominence to bird flu. In fact, of the total space alloted to health risk issues in the PhilStar and the Bulletin, more than half $(58.03 \%$ and $53.20 \%$, respectively) were occupied by bird flu. Among the three newspapers, the Inquirer had the least space (47.58\%) devoted to bird flu.

Food poisoning came second. Both the Inquirer (31.06\%) and the PhilStar (21.88\%) made it second to bird flu. The Bulletin, however, gave it the least $(15.85 \%)$. Overall, the least prominent health risk issues in the three newspapers were meningococcemia and dengue fever.

Generally, the three newspapers gave less importance to the health risk articles. This could be gleaned from the results showing that a big proportion of these articles $(87.02 \%)$ were located in the inside page. Only a few $(12.98 \%)$ were located in the front pages of the newspapers (Table 5).

On a per issue basis, more than a third (37.50\%) of the articles on food poisoning were located in the front page, while only a few of the articles on bird flu (4.72\%) and dengue fever (2.94\%) were located in the front pages. All articles on meningococcemia were located in the inside pages. Of the four 
Table 4. Space allocated to health risk articles and other categories in the sample newspapers $^{\mathrm{a}}$

\begin{tabular}{llll}
\hline Units of analysis & \multicolumn{3}{c}{ Newspapers } \\
\cline { 2 - 4 } & Inquirer & Bulletin & PhilStar \\
\hline Other articles & $8,060,839.30$ & $13,414,062.00$ & $7,391,393.90$ \\
Health risks & & & \\
$\quad$ Bird flu & $14,500.74$ & $19,825.40$ & $13,031.65$ \\
$\quad$ Dengue & $6,898.72$ & $10,563.93$ & $7,561.80$ \\
$\quad$ Food poisoning & $1,300.50$ & $4,081.07$ & $1,059.25$ \\
$\quad$ Meningococcemia & $4,503.85$ & $3,142.80$ & $2,851.90$ \\
Percent of Space & & 0.148 & 0.148 \\
Allocated to Health risks & 0.180 & \\
${ }^{a}$ No significant differences were detected by the one-way & ANOVA $\left(F_{(2,205)}=2.29\right.$, \\
\multicolumn{2}{l}{$p>.05)}$.
\end{tabular}

health risks, food poisoning was given more prominence, while meningococcemia was the least.

For news making, results showed that many of the articles in the three national newspapers (76.56\% in the Inquirer, $86.32 \%$ in the Bulletin, and $83.67 \%$ in the PhilStar) were prompted by experiences of the public.

Data showed that expert sources and government officials were quoted in more than half of the health risk articles in the three newspapers. More specifically, experts were quoted in more than two-thirds $(67.35 \%)$ of the PhilStar articles. A similar number of articles (65.62\%) quoting experts were published in the Inquirer, while more than half (52.63\%) of the articles in the Bulletin quoted experts.

In offering explanations for risk events, both the Bulletin and the PhilStar were more likely to emphasize organizational or structural failures than personal failures or errors. More than half (57.14\%) of the health risk articles in the PhilStar emphasized organizational failures compared to almost a third (32.65\%) which emphasized personal errors. Similarly, more than two-fourths $(46.32 \%)$ of the health risk articles in the Bulletin blamed or assigned responsibility to organizations compared to less than a third $(32.63 \%)$ which blamed or assigned responsibility to individuals. The Inquirer, on the other hand, assigned blame and responsibility to individuals rather than to organizations with more than a third (39.06\%) of its health risk articles attributing blame and responsibility to personal errors. More than a third (34.38\%) of its articles emphasized organizational failures (Table 6). 
Table 5. Placement of health risk articles

\begin{tabular}{llll}
\hline Placement & \multicolumn{3}{c}{ Newspapers } \\
\cline { 2 - 4 } & Inquirer & Bulletin & PhilStar \\
\hline Front Pages & 9 & 5 & 7 \\
Number & 14.06 & 5.26 & 14.29 \\
Percent & & & \\
Inside Pages & 55 & 90 & 42 \\
Number & 85.94 & 94.74 & 85.71 \\
Percent &
\end{tabular}

Table 6. Sources of information for the health risk articles

\begin{tabular}{lllllll}
\hline Aspect of coverage & \multicolumn{7}{c}{ Newspapers } \\
\cline { 2 - 7 } & \multicolumn{7}{l}{ Inquirer \% } & Bulletin \% & PhilStar \% \\
\hline News making & 15 & 23.43 & 17 & 17.89 & 8 & 16.33 \\
$\quad$ Scientific activities & 49 & 76.56 & 82 & 86.32 & 41 & 83.67 \\
$\quad$ Experiences of the public & & & & & & \\
Access to voice & 42 & 65.62 & 50 & 52.63 & 33 & 67.35 \\
$\quad$ Experts & 35 & 54.69 & 70 & 73.68 & 34 & 69.39 \\
$\quad$ Government officials & 10 & 15.62 & 11 & 11.5 & 8 & 16.33 \\
$\quad$ Ordinary members of the public & & & & & & \\
Assignment of responsibility & & & & & & \\
and blame & 25 & 39.06 & 31 & 32.63 & 16 & 32.65 \\
$\quad$ Personal failures & 22 & 34.38 & 44 & 46.32 & 28 & 57.14 \\
$\quad$ Organizational failures & & & & & & \\
\hline
\end{tabular}

\section{Time periods of the health risk articles}

Time periods refer to the periods when the health risk articles were published. The health risk articles were divided according to three time periods to take into account significant changes in the space allocation and language used from January 2005 to December 2005. The three time periods were pre-peak, peak, and post-peak. The pre-peak period was composed of articles published before the peak in media interest. The peak period included articles published during the peak in media interest, while the post-peak period included articles published after the peak interest period. These three periods allowed comparisons between each newspaper across three time periods. The periods of the health risk are presented in Table 7.

For bird flu, the pre-peak period was from January to October 2005, the peak period was in November 2005, and the post-peak was in December 2005. Bird flu articles in the pre-peak period featured threats of a looming bird flu pandemic. Most of the articles were on the prediction of experts about the mutation of the virus, its global effects and bird flu incidence in Asia. Towards 
Table 7. Time periods of the health risk issues in the leading Philippine newspapers

\begin{tabular}{llll}
\hline Health Risk Issues & Pre-Peak & Peak & Post-Peak \\
\hline Bird flu & January-October & November & December \\
Dengue fever & January-July & August-December & - \\
Meningoccemia & - & January & February-December \\
Food poisoning & - & March & April-December \\
\hline $\begin{array}{r}\text { Note: } \text { Meningoccemia } \\
\text { fever did not a }\end{array}$ & post-peak period.
\end{tabular}

Table 8. Space allocation of health risk articles through time periods

\begin{tabular}{|c|c|c|c|c|}
\hline \multirow[t]{2}{*}{ Time periods } & \multicolumn{4}{|c|}{ Space allocation of health risks (in $\mathrm{cm}^{2}$ ) } \\
\hline & Bird flu & Dengue & $\begin{array}{l}\text { Food } \\
\text { poisoning }\end{array}$ & Meningococcemia \\
\hline \multicolumn{5}{|l|}{ Inquirer $^{\mathrm{a}}$} \\
\hline Pre-peak & $3,855.20$ & 369.50 & - & - \\
\hline Peak & $2,060.50$ & 931.50 & $4,461.10$ & $1,428.27$ \\
\hline Post-peak & 982.03 & - & 42.75 & 369.40 \\
\hline \multicolumn{5}{|l|}{ Bulletin $^{\mathrm{a}}$} \\
\hline Pre-peak & $6,357.93$ & $1,111.32$ & - & - \\
\hline Peak & $3,024.00$ & $2,629.75$ & $2,932.05$ & $1,030.47$ \\
\hline Post-peak & $1,182.00$ & - & 210.75 & 498.75 \\
\hline \multicolumn{5}{|l|}{ PhilStar } \\
\hline Pre-peak & $3,269.55$ & 836.25 & - & - \\
\hline Peak & $3,801.25$ & 223.00 & $2,851.90$ & 962.70 \\
\hline Post-peak & 491.00 & - & - & 596.00 \\
\hline
\end{tabular}

${ }^{a}$ No significant differences were detected by the one-way ANOVA across time periods

in Inquirer $\left(F_{(2,32)}=2.29, p>.05\right)$ and in Bulletin $\left(F_{(2,42)}=0.19, p>.05\right)$.

the end of the pre-peak period and during the peak and the post-peak periods, national and international agencies were coming up with solutions to avert the threat, or if not, to cope with it. This includes the publicity of Tamiflu which is said to be a vaccine against the bird flu virus.

For dengue fever, the pre-peak was from January to July 2005 and the peak period was from of August to December 2005. This is understandable because in the Philippines, August and September are also the months when dengue fever incidence is high. During the first few months of the year, only dengue fever incidence was reported. During the start of the rainy season, and the month before that, local governments started implementing clean-up drives and other activities to combat the disease. Most articles focused more on the prevention of dengue fever during the peak period.

Since the food poisoning incident involving cassava in Bohol erupted only in March 2005, this issue did not have a pre-peak period. The peak period was in March and the post-peak was from April to December 2005. 
However, the PhilStar did not publish any article regarding food poisoning in the post-peak period. Days after that tragedy in Bohol, the articles regarding guidelines on canteen and food handling in public schools were emphasized. Even new guidelines in pesticide handling were formulated. Facts about cassava, its toxicity and proper preparation, swamped the newspapers. After the information awareness campaign, only brief reports on food poisoning involving cassava were published.

Meningococcemia had no pre-peak period since its peak period was in January 2005. The post-peak period was from February to December 2005. During the peak period, the focus was on meningococcemia's incidence in Baguio and its effects on Baguio's tourism industry.

Data showed that the Inquirer and the Bulletin gave greater space to bird flu articles during the pre-peak period compared to the peak and postpeak periods $\left(3,855.2 \mathrm{~cm}^{2}, 2,060.5 \mathrm{~cm}^{2}\right.$, and $982.03 \mathrm{~cm}^{2}$, respectively for the Inquirer and 6,357.93 $\mathrm{cm}^{2}, 3,024 \mathrm{~cm}^{2}$, and $1,182 \mathrm{~cm}^{2}$, respectively for the Bulletin). This was because the pre-peak period stretched to 10 months - that is, from January to October, compared to the peak period which was set for only a month. There was only a slight difference in the space allotted between the pre-peak and the peak period in the PhilStar. Data showed that from $3,269.55 \mathrm{~cm}^{2}$ in the pre-peak period, space allocation dropped to $3801.25 \mathrm{~cm}^{2}$ in the peak period, then dropped again to $491 \mathrm{~cm}^{2}$ in the postpeak period. However, the ANOVA showed no significant difference in space allocation between time periods between the Inquirer and the Bulletin. For PhilStar, the ANOVA could not be performed because there were less than 30 samples.

For dengue fever, results showed an increase in space allocation from the pre-peak to the peak periods in the Inquirer $\left(369.5 \mathrm{~cm}^{2}\right.$ and $931 \mathrm{~cm}^{2}$, respectively) and the Bulletin (1,111.32 $\mathrm{cm}^{2}$ and 2,629.75 $\mathrm{cm}^{2}$, respectively). In the case of PhilStar, however, a greater space was allotted during the prepeak period than the peak period $\left(8,36.25 \mathrm{~cm}^{2}\right.$ and $223 \mathrm{~cm}^{2}$ respectively). This was because there were more articles in the pre-peak than in the peak period for the PhilStar.

As regards food poisoning, results revealed a considerable decrease in the space allocated for these articles from the peak to the post-peak period by the Inquirer ( $4461.1 \mathrm{~cm}^{2}$ and $42.75 \mathrm{~cm}^{2}$, respectively) and the Bulletin $\left(2,932.05 \mathrm{~cm}^{2}\right.$ and $210.75 \mathrm{~cm}^{2}$, respectively). The PhilStar $\left(2,851.9 \mathrm{~cm}^{2}\right)$ did not publish any article after the peak period. 
Data also showed that space allocated to meningococcemia articles decreased in the three newspapers. In fact, in the Inquirer, the space alloted for meningococcemia articles reduced by around one-third from the peak period to the post-peak period $\left(1,428.27 \mathrm{~cm}^{2}\right.$ and $369.40 \mathrm{~cm}^{2}$, respectively). In the Bulletin, the decrease was more than half $\left(1,030.47 \mathrm{~cm}^{2}\right.$ and 498.75 $\mathrm{cm}^{2}$, respectively). In the PhilStar, space allocation decreased by about half $\left(962.7 \mathrm{~cm}^{2}\right.$ and $596 \mathrm{~cm}^{2}$, respectively). Table 8 shows the space allotted to health risk articles across time periods. In most cases, the space allotted to health risk articles in the peak period was greater compared to the space allotted to health risk articles during the other two periods. This was because the number of health risk articles increased and were longer during the peak period.

\section{Negative emotion words in health risk messages}

The objective of this study was to find out the amplification of health risk messages in the newspapers. Thus, health risk articles identified in the content analysis were lexically analyzed through the LIWC. The analysis focused on negative emotions, words linked to people's ratings of anxiety. It was assumed that an increase of negative emotion words in the health risk articles would indicate intensification, thus amplification of health risks. It was also assumed that the increase in the negative emotion words would be in the peak period of media interest.

Data showed a pattern of increase and decrease in the number of negative emotion words. However, this pattern was different from the assumption that there was a greater percentage of negative emotion words in the peak than in the pre-peak and post-peak periods. For instance, Table 9 shows that the percentage of negative emotion words increased in bird flu articles published by the PhilStar from the pre-peak to the peak period, then a decrease from the peak to the post-peak period. Dengue fever articles in the Inquirer and the Bulletin published during the peak period had a greater percentage of negative words, indicating intensification. In short, health risks in the Inquirer and Bulletin published during the peak period were amplified.

In general, bird flu articles in the Inquirer and the Bulletin, dengue fever articles in the PhilStar, food poisoning articles in the Bulletin and meningococcemia articles in the three newspapers were less intensified during the peak period as these articles were found to have less percentage of negative emotion words than the articles during the pre-peak and post-peak periods. 
Table 9. Mean percentage of negative emotion words in health risk articles among time periods

\begin{tabular}{lllll}
\hline Time periods & \multicolumn{4}{c}{ Space allocation of health risks $\left(\mathrm{in} \mathrm{cm}^{2}\right)$} \\
\cline { 2 - 5 } & Bird flu & Dengue & $\begin{array}{l}\text { Food } \\
\text { poisoning }\end{array}$ & Meningococcemia \\
\hline $\begin{array}{l}\text { Inquirer } \\
\text { Pre-peak }\end{array}$ & 1.85 & 1.03 & - & - \\
Peak & 1.10 & 1.12 & 3.88 & 1.52 \\
$\quad$ Post-peak & 1.16 & - & 0 & 2.62 \\
Bulletin & & & & \\
Pre-peak & 1.42 & 0.97 & - & - \\
Peak & 1.26 & 1.22 & 2.72 & 1.77 \\
Post-peak & 1.56 & - & 4.17 & 2.88 \\
PhilStar & & & & - \\
Pre-peak & 1.52 & 2.89 & - & 1.98 \\
Peak & 2.11 & 0.66 & 3.31 & 2.34 \\
Post-peak & 1.54 & - & 0 & \\
\hline
\end{tabular}

\section{IMPLICATIONS AND RECOMMENDATIONS}

In general, the three national newspapers did not give much prominence to the four health risks. This is evidenced by two important results: 1) only a small space was alloted to health risk articles by the newspapers, and 2) a great number of these articles were placed in the inside pages. In contrast, political news dominated the newspapers' newshole and front pages. Considering the fact the newspapers dealt with in this study were the country's leading national newspapers, the above results highlight that the news media in the Philippines have continued to emphasize politics and relegated health risk issues to the background.

Worth highlighting here is that more than half of the health risk articles quoted experts. In other words, the reporters have tried to get expert opinion. Seem to be lacking, however, is the use of the scientific publications like the journals. In risk reporting, reliance on expert opinions could be disadvantageous as experts tend to highlight the angles related to their field of specialization. It is important to use scientific publications for the following reasons: 1) they protect the public from biases and agenda that may be inherent in expert opinion statements, thus allowing the public to formulate their own opinion on issues at risk, and 2) they amplify the dissemination of evidences to the general research community (Wilson et al., 2004). 
Results also showed that along with experts, government officials were also quoted in more than half of the health risk articles. In this study, articles that quoted both experts and government officials provided information about the disease, prevention measures and what the government is doing to combat diseases. However, most articles quoting only government officials tended to focus only on the governments' plans and programs to combat the disease and the officials' opinions that are often unscientific. It is, therefore, suggested that news writers limit their reliance on government officials as sources of information. With government officials as information sources, chances are all angles of the issue cannot be presented, thus, defeating the educational role of newspapers.

Results of this study revealed that responsibility and blame were mostly assigned to organizations rather than to individuals. This is understandable because the health risks involved in this study were those concerning international laws and those beyond the control of an individual (i.e., smuggling and migration of birds for bird flu). Therefore, the responsibility lies on government and international agencies to work together to stop the spread of the diseases. While this practice is acceptable, it might help if the articles will also highlight the fact that individuals can also help mitigate the risks posed by the disease to cultivate that sense of responsibility among readers.

The LIWC found that a considerable number of negative emotion words in the health risk articles. This implies that the health risks in the articles were intensified. In short, the newspapers bloated the risks. This is not helpful because based on research, intensifying issues, especially health risks, would result in unreasonable public outrage (Sandman and Lanard, 2005).

The above findings invariably underscore the fact that health reporting in the Philippines remains wanting. It is, therefore, suggested that interventions be designed to alleviate this situation. Thus, apart from seminars to improve journalists' appreciation of the value of health risks reporting, workshops should also be conducted to improve their reporting skills on risk issues. An area for training should be in the use of various information sources like the scientific journals and improving these journalists' understanding of technical terms involved in risks. Since journalists are purveyors of information, it is a must that they are well-versed in the scientific lingo used in risk communication.

Communication and journalism curricular programs can also help if they integrate risk reporting in their courses. These courses should develop students' competence in the technical terms in risk issues and hone their skills in packaging risk messages. 
In the meantime that our corps of reporters and editors lack technical know-how in health risk reporting, government agencies whose mandate relates to risk communication should design strategic communication drives to properly educate the public about risks. Proper education will lead the public to make informed decisions on how to deal with risks brought about by incidents and spread of diseases.

\section{LITERATURECITED}

Breakwell, G. M., Barnett, J., Lofstedt, R., Kemp, R., Glaser, C. (2001). The impact of social amplification of risk on risk communication. Contract Research Report. University of Surrey, United Kingdom.

Cassels, A., Hughes, M. A., Cole, C., Mintzes, B., Lexchin, J., McCormack, J. P. (2003, April). Drugs in the news: An analysis of Canadian newspaper coverage of new prescription drugs. Canadian Medical Association Journal. 168(9): 1133-1137.

Covello, V. T. Bridging. PDF Retrieved November 10, 2005 from the World Wide Web: http://www.cdc.gov/communication/emergency/features/ Covello_bridging.pdf\#search='covello $\% 20$ bridging

Kasperon, R.E, Renn, O., Slovic, P., \& Brown, H.S. (1988). The social amplification of risk: A conceptual framework. Risk Analysis, 8(2): 177-187.

Nilsson, A., Reitan, J. B., Tonnessen, A., Waldahl, R. (1997) Radiation and other risk issues in Norwegian newspapers ten years after Chernobyl. Report 1997: 8, Norwegian Radiation Protection Authority, Osteras.

Rodrigue, C. M. (2001, July). The Internet in the social amplification and attenuation of risk. Retrieved October 1, 2005 from the World Wide Web: http://www.csulb.edu/ $\sim$ rodrigue/

Sandman, P. M., Lanard, J. (2005). Bird flu: Communicating the risk. Perspectives in Health 10(2), 2-9.

Waishwell, L., Lowrie, K. (2005). Reporting of risks in newspapers: An Example of a content analysis. Retrieved December 5, 2005 from the World Wide Web: http:// depts.washington.edu/ fmrwrkr/1998conference/206.html

Wilson, K., Code, C., Dornan, C., Alimad, P. H., Graham, J. (2004). The reporting of theoretical health risks by the media: Canadian newspaper reporting of potential blood transmission of Creutzfeldt-Jakob disease. BMC Public Head, 4(1). 